\title{
Laidunalueiden fosfori ja kalium
}

\author{
Håkan Jansson, Markku Yli-Halla ja Hanna-Riikka Tuhkanen \\ MTT, Maa- ja elitarviketalouden tutkimuskeskus, 31600 Jokioinen, etunimi.sukunimi@mtt.fi
}

\section{Johdanto}

Laiduntaminen vähentää nurmen kasvipeitteisyyttä, ja joiltain kohdin kasvipeite kuluu kokonaan pois. Kasvipeitteettömiä alueita ovat useimmiten laitumille johtavat kulkuväylät, lisäruokintapaikat, lypsyjonotusalueet, kivennäisten syöttöpaikat, juottopaikat ja lehmien suosimat oleskelupaikat. Karjatalouden aiheuttaman vesistökuormituksen on uskottu häviävän, kun lantaloista tulevat suorat päästöt loppuvat (Rekolainen 1993). Rehtijärviprojektissa mitattiin liuenneen fosforin kuormitus erikseen peltoalueilta, joilla ei ollut suurta kuormitusta tuottavia alueita. Pelloilta tuleva kuormitus oli vain noin puolet valuma-alueelta tulevasta kokonaiskuormituksesta (Jansson 1998a). Tämän katsottiin viittaavan siihen, että valuma-alueella esiintyi melkoisesti karjatalouteen liittyvää pistemäistä kuormitusta, mistä läheskään kaikkea ei voitu paikallistaa karjasuojista tulevaksi. Lehmien ulkoilualueen valumaveden liuenneen fosforin pitoisuus oli alueen peltovesiin nähden yli 20kertainen (Jansson 2000). Tällaisilta alueilta tulevaan vesistökuormitukseen ei Suomessa ole kiinnitetty sanottavaa huomiota, ja tämä pistemäinen kuormitus sisältyy peltoviljelystä tulevaksi laskettuun ravinnekuormitukseen. Rehtijärviprojektissa havaittiin että korkea maan fosfori (viljavuusanalyysi) heijastui ojavesien kohonneina pitoisuuksina (Jansson 1998b).

Lypsylehmän ulosteet, pääasiassa virtsa, sisältävät kaliumia noin $80 \mathrm{~kg}$ vuodessa, ja osa siitä joutuu laitumelle. Ulosteet sisältävät 95-100 \% rehujen kaliumista. Virtsan kaliumpitoisuus on $6500 \mathrm{mg} / \mathrm{l}$. Vaikka nurmirehun korkea kaliumpitoisuus heikentää rehun laatua, laitumilla mahdollisesti esiintyviin arveluttavan korkeisiin maan kaliumpitoisuuksiin ei ole kiinnitetty huomiota.

Tässä tutkimuksessa selvitettiin ensisijaisesti laitumien ja niillä olevien ruokinta- ja juottopaikkojen maan ja laitumilta tulevien valumavesien fosforipitoisuutta, jotta saadaan tarkempi käsitys tällaisten paikkojen aiheuttamasta fosforikuormituksesta. Samalla mitattiin maan ja valumavesien kaliumpitoisuus.

\section{Aineisto ja menetelmät}

Laidunnuksen ympäristökuormituksen selvittämiseksi tutkittiin pintamaan $(0-2 \mathrm{~cm})$ fosfori- ja kaliumpitoisuuksia hietasavimaalla olevalla lypsylehmien laidunalueella Vesilahdella (23 näytettä. Näytteitä otettiin sekä kasvipeitteisiltä että paljaiksi kuluneilta alueilta. Noin aarin alalta otetut näytteet koostuivat viidestä osanäyteestä. Näytteenottoalue oli lohko, jossa lisäruokinta järjestettiin, kun laidunruohoa ei enää ollut syksyisin riittävästi. Näytteitä ei otettu paikoista, missä lantaa oli havaittavissa. Osassa näytteenottopaikoista lantaa tosin oli sotkeutunut pintakerrokseen. Laidun oli ollut käytössä kolme vuotta. Tilalla lypsylehmiä on 35, ja suuri osa pelloista on taloudellista lannankäyttöä ajatellen liian kaukana. Vesinäytteiden saamiseksi maasta otettiin lieriönäytteitä, joita sadetettiin laboratoriossa. Sadetettavaksi otettiin maalieriöitä Vesilahden laitumelta, MTT:n hiehojen ruokintapaikalta Jokioisten Nummelan tilalta, Tammelan Mustialan vasikoiden laitumelta, ja Mustialan ohrapellolta. Näytteitä sadetettiin laboratoriossa viisi tuntia. Tässä esityksessä käsitellään sadetuskokeen pintavalunnasta otettuja näytteitä, joista määritettiin liuennut fosfori ja kalium sekä kokonaisfosfori. Maanäytteistä tehtiin viljavuusanalyysi uuttamalla näytteitä happamalla ammoniumasetaattiliuoksella ( $\mathrm{pH} 4.65)$.

\section{Tulokset}

Maan fosfori- ja kaliumpitoisuudet

Vesilahden laitumen pintamaasta $(0-2 \mathrm{~cm})$ kerättyjen näytteiden fosforipitoisuuksien vaihteluväli oli 4.6 - $1180 \mathrm{mg} / \mathrm{l} \mathrm{ja}$ mediaani $90 \mathrm{mg} / \mathrm{l}$. Suurin pitoisuus mitattiin edellisvuoden ruokintapaikalta. Fosforipitoisuus ylitti $100 \mathrm{mg} / \mathrm{l}$ yhteensä 10 näytteessä, joista vain yksi oli normaalilta nurmea kasvavalta alueelta. Nurmea kasvavien alueiden fosforipitoisuudet olivat 
46-136 mg/l. Ruokintapaikkojen lisäksi korkeita pitoisuuksia mitattiin navettaporttialueelta ja karjapoluilta. Vain laidunlohkon lannoittamattoman järvenranta-alueen fosforipitoisuudet (3.5 $-25.5 \mathrm{mg} / \mathrm{l}$ ) olivat pienempiä kuin arveluttavan korkeita.

Kaliumin pitoisuus pintamaassa korreloi kiinteästi fosforipitoisuuden kanssa (Kuva 1). Kaliumpitoisuus on arveluttavan korkea, kun se on savimailla yli $800 \mathrm{mg} / \mathrm{l}$ ja hiedoilla yli 500 $\mathrm{mg} / \mathrm{l}$. Arveluttavan korkeita pitoisuuksia oli ruokintapaikoilla ja vastaavissa paikoissa mutta myös laitumien kasvipeitteisissä osissa. Kaliumpitoisuus oli arveluttavan korkea tutkittujen laitumien muokkauskerroksessa sekä yhden ruokintapaikan ja portin edustan jankossa (Taulukko 1). Koska myös magnesiumpitoisuudet olivat korkeita, magnesiumin ja kaliumin suhde muokkauskerroksessa oli kuitenkin tyydyttävä $(0,33-0,5)$.

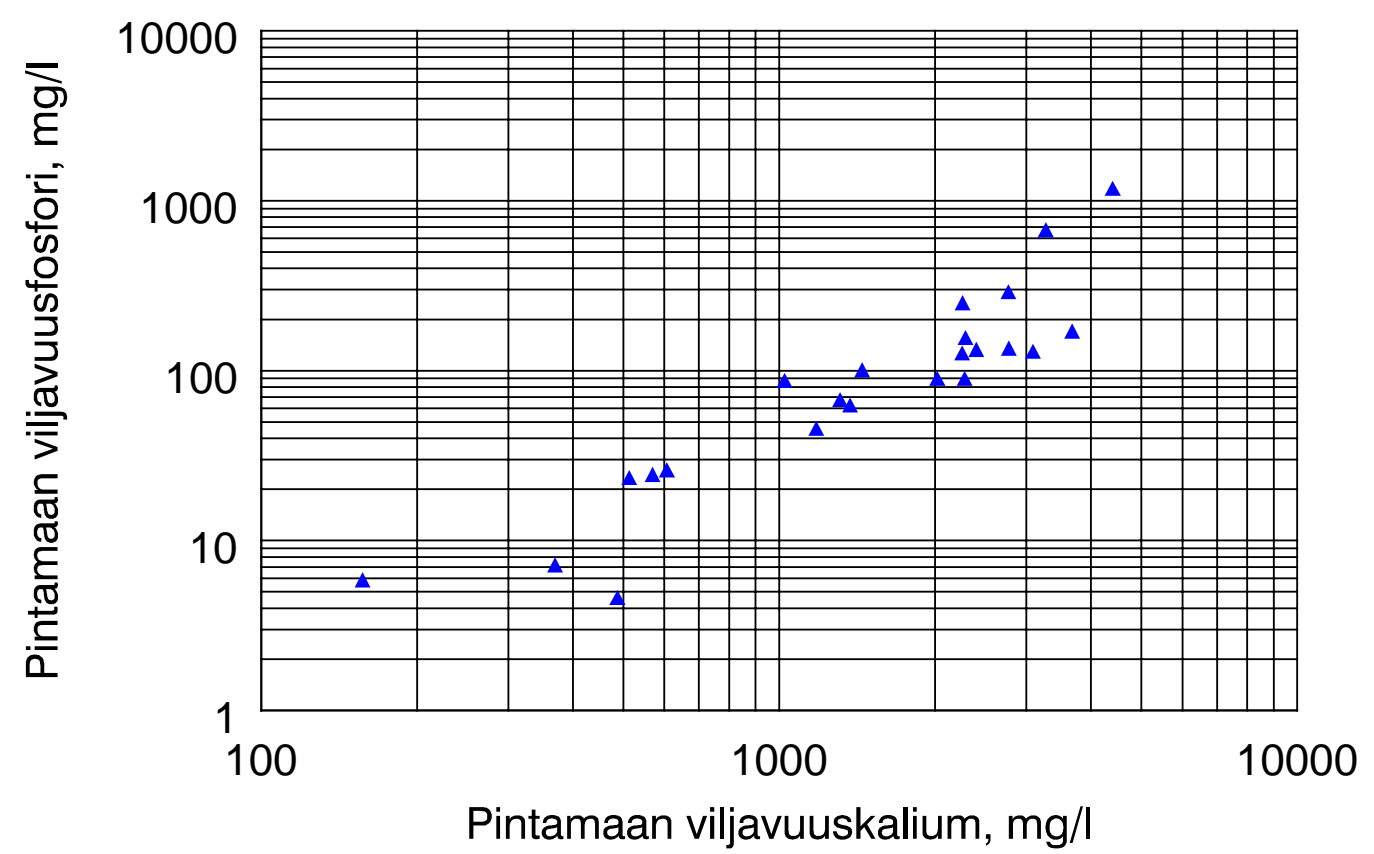

Kuva 1. Laitumilta kerättyjen pintamaanäytteiden kalium- ja fosforipitoisuudet.

Taulukko 1. Neljän maaprofiilin kerrosnäytteiden fosforipitoisuus (P) ja kaliumpitoisuus (K) sekä ravinnesuhteet $\mathrm{Mg} / \mathrm{K}$ ja $\mathrm{Mg} / \mathrm{Ca}$.

\begin{tabular}{|l|l|l|l|l|l|r|r|r|}
\hline Syvyys, $\mathrm{cm}$ & \multicolumn{4}{|l|}{$\begin{array}{l}\text { Ruokintapaikka } \\
\text { Portin edusta }\end{array}$} & \multicolumn{4}{l|}{ Laidun $(2 \mathrm{kpl})$} \\
\hline & $\mathrm{P}, \mathrm{mg} / \mathrm{l}$ & $\mathrm{K}, \mathrm{mg} / \mathrm{l}$ & $\mathrm{Mg} / \mathrm{K}$ & $\mathrm{Mg} / \mathrm{Ca}$ & $\mathrm{P}, \mathrm{mg} / \mathrm{l}$ & $\mathrm{K}, \mathrm{mg} / \mathrm{l}$ & $\mathrm{Mg} / \mathrm{K}$ & $\mathrm{Mg} / \mathrm{Ca}$ \\
\hline $0-2$ & 401.7 & 3180 & 0.35 & 0.39 & 35 & 1146 & 0.33 & 0.18 \\
\hline $2-20$ & 72.5 & 1570 & 0.38 & 0.24 & 28 & 913 & 0.31 & 0.14 \\
\hline $20-40$ & 21.9 & 1840 & 0.23 & 0.25 & 21 & 448 & 0.55 & 0.13 \\
\hline $40-60$ & 8.1 & 500 & 1.4 & 0.34 & 11 & 272 & 0.88 & 0.17 \\
\hline $60-80$ & 2.2 & 360 & 2.7 & 0.39 & 5 & 235 & 1.61 & 0.25 \\
\hline $80-100$ & 1.5 & 230 & 4.1 & 0.43 & 2 & 222 & 1.99 & 0.29 \\
\hline
\end{tabular}

\section{Sadesimuloinnin tulokset}

Sadesimuloinneissa laitumien ruokintapaikoilta otetuista näytteistä (Taulukko 2) tulleiden pintavesinäytteiden veteen liuenneen kaliumin pitoisuus oli aluksi yli $50 \mathrm{mg} / \mathrm{l}$. Pitoisuus aleni sadetuksen kuluessa muutamassa tunnissa noin $10 \mathrm{mg} / \mathrm{l}$ :aan. Liuenneen fosforin huuhtoutuminen muistutti kaliumin huuhtoutumista siten että fosforin pitoisuus huuhtoutuvissa pintavesissä oli aluksi korkein $(3.9 \mathrm{mg} / \mathrm{l})$ ja aleni loppua kohti $(2.3 \mathrm{mg} / \mathrm{l})$. Jos 
pintavaluntaa tulee $200 \mathrm{~mm}$ vuodessa ja keskimääräinen fosforin pitoisuus on $3 \mathrm{mg} / \mathrm{l} \mathrm{ja}$ kaliumpitoisuus $20 \mathrm{mg} / \mathrm{l}$, tältä paikalta huuhtoutuu $6 \mathrm{~kg} / \mathrm{ha}$ liuennutta fosforia ja $40 \mathrm{~kg} / \mathrm{ha}$ liuennutta kaliumia vuodessa.

Taulukko 2. Neljän sadetetun lieriönäytteen kalium- ja fosforipitoisuudet pintamaassa (0-2 $\mathrm{cm})$ ja pintavalumavedessä.

$\begin{array}{ccccc} & \mathrm{K}, \mathrm{mg} / \mathrm{l} \text { mata } & \begin{array}{c}\text { Valumaveden } \\ \text { liuennut } \mathrm{K}, \mathrm{mg} / \mathrm{l}\end{array} & \mathrm{P}, \mathrm{mg} / \mathrm{l} \text { mata } & \begin{array}{c}\text { Valumaveden } \\ \text { liuennut } \mathrm{P}, \mathrm{mg} / \mathrm{l}\end{array} \\ \text { Vanha ruokintapaikka } & 3090 & 26.4 & 130 & 3.0 \\ \text { Hiehojen ruokintapaikka } & 1381 & 24.1 & 154 & 2.9 \\ \text { Vasikkalaidun } & 1111 & 3.9 & 24 & 0.3 \\ \text { Ohrapelto } & 224 & 0.9 & 38 & 0.3\end{array}$

\section{Tulosten tarkastelu}

Sänkipellon (maan fosforipitoisuus $3.2 \mathrm{mg} / \mathrm{l}$ maata) sadesimuloitikokeissa (Turtola \& Pitkänen 1997) mitattiin vain hieman alhaisempia pintamaan valumavesien pitoisuuksia (0.25 mg/l) kuin tämän kokeen vasikkalaitumelta ja ohrapellolta, jonka fosforipitoisuus oli melko korkea mutta Turtolan \& Pitkäsen (1997) kokeessa kynnetyn alueen näytteistä saatu tulos oli paljon pienempi $(0.028 \mathrm{mg} / \mathrm{l})$. Suomen pelloilta tulevien valumavesien keskimääräinen liuenneen fosforin pitoisuus on $0.1 \mathrm{mg} / \mathrm{l}$ (Rekolainen 1993). Tässä tutkimuksessa laidunalueiden ongelmakohteiden pintavesinäytteissä mitattiin monikymmenkertaisia pitoisuuksia.

Viljanviljelyssä kaliumin huuhtoutuminen pintavalunnassa ja salaojavedessä savimaalla on ollut noin $10 \mathrm{~kg} / \mathrm{ha}$ ja nurmella $15 \mathrm{~kg} / \mathrm{ha}$ (Turtola ja Jaakkola 1986). Laitumilta huuhtoutuu paikoitellen siis runsaasti kaliumia. Kaliumin huuhtoutuminen ei kuitenkaan ole ympäristöongelma.

Profiilinäytteistä tehdyt määritykset osoittavat, että fosforia ja kaliumia kertyy laitumien pintamaahan. Fosforin kertyminen rajoittuu yleensä muutaman sentin pintakerrokseen. Neljässä tutkitussa paikassa oli kaliumia runsaasti koko muokkauskerroksessa ainakin näytteenottoalueilla. Nurmien uudistaminen kyntämällä sekoittaa ohuen pintamaan runsaat ravinnevarat muuhun muokkauskerrokseen. Mutta jos muokkauskerroksen kaliumpitoisuus on jo kauttaaltaan arveluttavan korkea, ei tilanne parane nurmea uudistettaessa.

\section{Johtopäätökset}

Laitumilta voi tulla pistemäistä fosforikuormitusta. Koska ravinnerikkaan pintakerroksen alapuolella oli maata, jonka fosforipitoisuus on paljon pienempi, ruokintapaikkojen pintamaan ajoittainen poisto voi olla tarpeen vesistökuormituksen vähentämiseksi. Lisäruokinta-alueen siivoaminen laidunkauden päätyttyä parantaisi ratkaisevasti tilannetta. Eläinten paljaaksi kuluttamilla paikoilla, joilla esiintyy korkeita kaliumpitoisuuksia, voi myöhemmin kasvaa ruohoa, jonka kaliumpitoisuus on eläimille liian korkea Olisikin syytä tutkia laidunruohon kaliumpitoisuuden vaihtelua tällaisilla laitumilla. Samat toimenpiteet, jotka tähtäävät fosforikuormituksen pienentämiseen voivat myös laskea laidunruohon korkeaa kaliumpitoisuutta.

\section{Kirjallisuusviitteet}

Jansson, H. 1998a. Maan helppoliukoinen fosfori valumavesien fosforipitoisuuden säätelijänä. In: Agro-Food '98 : Tampere 3.-5.2.1998, Tampere-talo. Agro-Food ry. p. E54

Jansson, H. 1998b. Rehtijärvi. In: Loimijoki-projektin raportti 1991-1997: ympäristöhankkeen eteneminen Loimijokilaakson maatiloilla ja jokirannoilla. Maatalouden tutkimuskeskus, Jokioinen. p. 43-48.

Jansson, H. 2000. Lypsykarjatilojen ravinnekuormitus kuriin. Koetoiminta ja käytäntö 57:6, p. 4 (http://www.maaseuduntulevaisuus.fi/cgi-bin/weblehti.exe) 
Jansson, H., Mäntylahti, V., Närvänen, A. \& Uusitalo, R. 2000. Phosphorus content of ditch sediments as indicator of critical source areas (Research Note). Agricultural and food science in Finland 9:3, 217-222

Rekolainen, S. 1993. Assessment and mitigation of agricultural water pollution. Publications of the Water and Environment Research Institute, Finland. No. 12.

Turtola, E. \& Jaakkola, A. 1985. Viljelykasvin ja lannoitustason vaikutus typen ja fosforin huuhtoutumiseen savimaasta. Maatalouden tutkimuskeskus. Tiedote 6/85: 43 p.

Turtola, E. \& Pitkänen, J. 1997. A rainfall simulation study on P losses from a clay soil under different tillage. In: NJF seminar nr. 271 : Phosphorus balance and utilization in agriculture - towards sustainability, Kungl.Skogs- och Lantbruksakademien, Drottninggatan 95B, Stockholm, 17-19 March, 1997. Nordisk jordbruksforskning 79, 3: p. 51. 